\title{
Influence of synoptic atmospheric conditions on movement of individual sea-ice floes in Fram Strait, late summer 2010
}

\author{
Jennifer A. KING, ${ }^{1 *}$ Grant R. BIGG, ${ }^{1}$ Richard $\mathrm{HALL}^{2+}$ \\ ${ }^{1}$ Department of Geography, University of Sheffield, Sheffield, UK \\ E-mail: jennifer.king@npolar.no \\ ${ }^{2}$ Kongsberg Satellite Services AS, Tromsø, Norway
}

\begin{abstract}
In this paper we investigate the effect on sea-ice movement of changes in the synoptic atmospheric conditions in late boreal summer 2010. Our study area is the western Fram Strait, a crucial passage for the transport of ice out of the Arctic basin. Ice dynamics here affect the movement of ice in the East Greenland Current, the transpolar drift and ice extent in the Arctic Ocean. In contrast to other times of the year, when the Fram Strait wind field is characterized by strong, persistent northerlies, we show that the weaker, more variable winds typical during late summer for the Fram Strait can slow movement of ice floes out of the area, thus slowing the export of ice from the Arctic Ocean at the end of summer, a time crucial for ice export. The Arctic Ocean could lose even more of the ice that survives the summer if this was not the case. This would leave the Arctic Ocean in an even more vulnerable position with regard to the amount of multi-year ice remaining the following summer.
\end{abstract}

KEYWORDS: atmosphere/ice/ocean interactions, ice/atmosphere interactions, remote sensing, sea ice, sea-ice dynamics

\section{INTRODUCTION}

This paper describes the movement of individual sea-ice objects in the Fram Strait in late-summer conditions. By latesummer conditions we mean that there is a lot of open water present and that the ice floes are those that have survived the summer melt in the Arctic Ocean. Freeze-up for the coming autumn has not yet begun. The Fram Strait is an important conduit for the export of ice from the Arctic (Kwok and Rothrock, 1999; Vinje, 2001; Kwok and others, 2004, 2013; Smedsrud and others, 2011; Hansen and others, 2013). Fram Strait sea-ice export is highly variable from daily to interannual scales (Brümmer and others, 2001, 2003; Tsukernik and others, 2009; Hansen and others, 2013). An increase in the volume of ice transiting the Fram Strait may be a contributing factor to recent loss of ice in the Arctic Ocean (Smedsrud and others, 2011).

Wind is the primary forcing mechanism for ice movement in the transpolar drift and into the Fram Strait. Sea-ice motion is sensitive to the passing of individual cyclones (Brümmer and others, 2001, 2003). The typical atmospheric pattern at sea-level pressure for the area is a high-pressure system over Greenland and an area of low pressure to the east of Svalbard (Tsukernik and others, 2009). This sets up northerly winds that act in the same direction as the East Greenland Current (EGC) to move ice rapidly out of the Arctic Ocean. This pattern is typically more pronounced in winter (OctoberMay) than in summer. We investigate the influence of weaker and more variable winds on ice movement in the western Fram Strait in late summer 2010. The sea-ice conditions in 2010, including an area of fast ice off the Greenland coast and development of a polynya to the east of this fast ice, are typical for the region (King, 2012). Ice movement through the Fram Strait at this time of year may be a key component for understanding ice loss from the Arctic Ocean and its impact

*Present address: Norwegian Polar Institute, Fram Centre, Tromsø, Norway. ${ }^{+}$Present address: Statoil, Stavanger, Norway. on changes to ice extent year-on-year (Hansen and others, 2013). Unfortunately the cross-correlation algorithms routinely used to generate ice-motion products from satellite data do not perform well in late-summer conditions for a variety of reasons: increased atmospheric water vapour; a wet sea-ice surface; or loose conditions with a high percentage of open water present (Kwok and Rothrock, 1999; Kwok and others, 2004). We showcase here the use of an object-tracking algorithm that is more suited to loose conditions than the cross-correlation algorithms.

\section{METHOD}

Ice motion vectors were generated from a series of 12 RADARSAT images acquired in the latter half of August 2010 (Table 1) using the ITSARI (Ice Tracking from SAR Imagery) algorithm, a semi-automated ice-tracking tool (Silva and Bigg, 2005; Hall and others, 2012; King, 2012). ITSARI is an ideal choice for sea-ice motion tracking in the ice conditions typically found in the Fram Strait in later summer, i.e. loose ice in open water and high spatial variation in speed and direction of ice movement, because under these conditions ice floes appear in the radar image as individual floes with distinctive shape, that are easily defined and tracked by this object-based algorithm. The algorithm does not distinguish between different ice types such as first-year and multi-year ice. As the images acquired were dual polarization, the $\mathrm{HH}$ and $\mathrm{HV}$ bands were combined using basic band mathematics (matrix addition) into one greyscale image prior to processing with the ITSARI algorithm. In brief, the algorithm has two stages: the identification of individual objects by image segmentation and brightness thresholding; and object matching using a one-dimensional shape representation based on the distance to the edge of the shape from the centre pixel, measured at $5^{\circ}$ intervals. The identification stage can be fully automated if the user sets the segmentation and brightness thresholds in advance. The tracking stage is semi-automated: the 


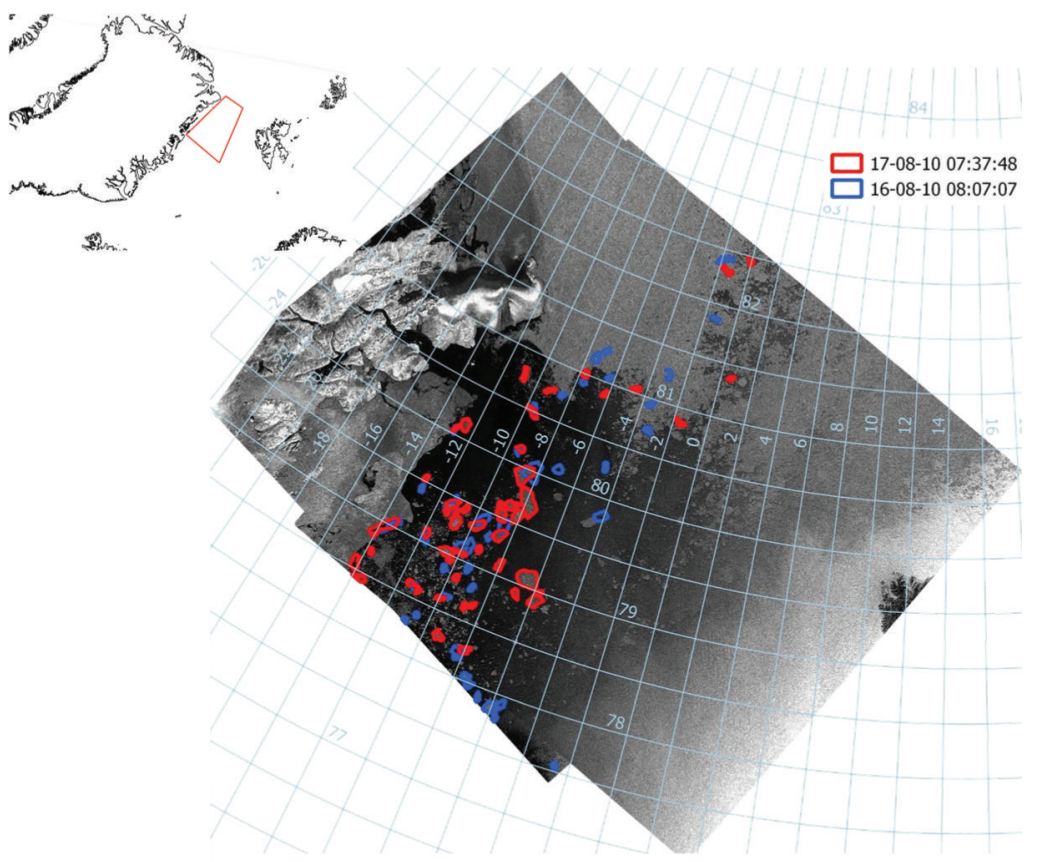

Fig. 1. Ice objects identified on 16 August (blue) and 17 August 2010 (red). The underlying images are from 16 and 17 August 2010 . Inset top left locates the study within the wider area.

computation of possible matches is carried out by the computer, then these are displayed on screen for the user to make a judgment as to whether the two objects are a true match or not. Silva and Bigg (2005) describe the development of the algorithm, and Hall and others (2012) and King (2012) describe its adaptation to use for sea-ice tracking.

The ice-motion vectors generated by ITSARI for late summer 2010 are compared to surface air pressure and wind speed and direction from the 20th-century reanalysis project (V2; Compo and others, 2011). Other reanalysis datasets show similar results. A variety of factors appear to be at play including katabatic winds moving ice offshore, and the effect of local wind patterns associated with the movement of pressure systems. The effects of localized meteorological conditions are traceable in the southward sea-ice flow in the EGC.

\section{RESULTS AND DISCUSSION}

Figure 1 shows how the types of identifiable and traceable objects appear on the first RADARSAT image from 16 August 2010. The East Greenland coast can be seen in the west of the image, with fast ice extending from the coast into the strait from $14^{\circ} \mathrm{W}$ to $8^{\circ} \mathrm{W}$. A polynya (area of open water) can be seen adjacent to the Greenland coast at $80-81^{\circ} \mathrm{N}$, extending into the strait to $\sim 6^{\circ} \mathrm{W}$ and south alongside the fast-ice edge. Many of the objects tracked in this study are floes moving across this polynya.

Table 1 details the number of objects tracked from each image pair, with average speed, distance and direction of travel for the tracked objects; and time elapsed and the area of overlap between the images in a pair. Over the duration of the project the mean direction of movement was southeastward. This is a reflection of the south-southwest

Table 1. Number of objects tracked from each image pair, with average speed, distance and direction of travel for the tracked objects; and time elapsed and the area of overlap between the images in a pair. Date format is dd-mm-yy

\begin{tabular}{|c|c|c|c|c|c|c|c|}
\hline Start date and time & End date and time & $\begin{array}{c}\text { Number of } \\
\text { matches }\end{array}$ & $\begin{array}{c}\text { Average speed } \\
\mathrm{m} \mathrm{s}^{-1}\end{array}$ & $\begin{array}{c}\text { Average distance } \\
\text { km }\end{array}$ & $\begin{array}{c}\text { Average direction } \\
\circ\end{array}$ & $\begin{array}{c}\text { Hours of } \\
\text { separation }\end{array}$ & $\begin{array}{c}\text { Overlap } \\
\mathrm{km}^{2}\end{array}$ \\
\hline 16-08-10 08:07 & 17-08-10 07:37 & 65 & $0.17 \pm 0.12$ & $14.5 \pm 10$ & $104 \pm 92$ & 24 & 190049 \\
\hline 17-08-10 07:37 & 19-08-10 08:19 & 22 & $0.14 \pm 0.05$ & $25.27 \pm 10$ & $210 \pm 44$ & 49 & 158731 \\
\hline 19-08-10 08:19 & 20-08-10 07:50 & 15 & $0.21 \pm 0.21$ & $18.01 \pm 18$ & $111 \pm 101$ & 23 & 180773 \\
\hline 23-08-10 08:02 & 24-08-10 07:33 & 24 & $0.29 \pm 0.04$ & $24.90 \pm 3$ & $28 \pm 66$ & 24 & 174272 \\
\hline 24-08-10 07:33 & 26-08-10 08:15 & 20 & $0.18 \pm 0.04$ & $30.86 \pm 7$ & $227 \pm 30$ & 49 & 143574 \\
\hline 26-08-10 08:15 & 30-08-10 07:58 & 22 & $0.10 \pm 0.05$ & $34.32 \pm 18$ & $107 \pm 45$ & 96 & 216067 \\
\hline 26-08-10 08:15 & 30-08-10 07:59 & 15 & $0.14 \pm 0.07$ & $48.92 \pm 25$ & $131 \pm 52$ & 96 & 35114 \\
\hline 30-08-10 07:58 & 31-08-10 07:29 & 37 & $0.38 \pm 0.07$ & $32.30 \pm 6$ & $29 \pm 9$ & 24 & 172213 \\
\hline 31-08-10 07:29 & 02-09-10 08:11 & 40 & $0.16 \pm 0.05$ & $27.75 \pm 8$ & $197 \pm 19$ & 49 & 142732 \\
\hline 02-09-10 08:11 & 03-09-10 07:41 & 50 & $0.13 \pm 0.06$ & $11.10 \pm 5$ & $57 \pm 87$ & 24 & 184032 \\
\hline
\end{tabular}


movement of the EGC, moderated by the prevailing wind, which that month was from the northwest. The general southward movement was punctuated by short episodes of about 1-2 days where ice moved in other directions defined by variations in wind direction on the same timescale, or local mesoscale eddies in the ocean. Pressure data and accompanying changes in wind strength and direction were taken from the 6 hourly reanalysis series to identify the relationship between sea-ice motion and wind forcing more fully than by taking the average wind direction over the interval encapsulated by an image pair. Because it may take 12-18 hours to set up a response to wind forcing, particularly for light winds, it is more likely that the movement we measure is related to wind forcing from earlier rather than later in the time period between images; we have selected the reanalysis data displayed accordingly. As a general rule, those image pairs closer in time produce a higher number of matched objects. There are exceptions to this (e.g. 37 objects are tracked from the image on 26 August 2010 to those on 30 August 2010, whereas only 15 objects are tracked between 19 and 20 August 2010). The relationship between the area of overlap and the number of objects tracked is even less clear. The pair with the largest overlapping area is 20-23 August 2010, but only 18 objects are tracked because the overlapping area contains both a large area of open water in the east and an area of close pack where individual objects are not distinguishable by the algorithm to the north. The relationship between area of overlap and number of objects tracked is also complicated by the speed and direction of movement, i.e. if an object moves out of the overlapping area it may still be tracked if it remains in the area covered by the second image.

Figure 2 shows the tracked ice-floe movement vectors (in red, with a dot marking the end of the track) with winds representative of the period (in blue) and sea-level pressure (hPa) from the 20th-century reanalysis (timing of reanalysis data is explained in the figure caption). The image overlap is normally centred within the cluster of vectors, but due to the differences in satellite orbit from day to day some image pairs have more overlap than others. The absence of vectors should not necessarily be interpreted as meaning no ice is present. To set this study into context, Figure $3 \mathrm{a}$ and $\mathrm{b}$ show the mean sea-level pressure between 1981 and 2010 for all months of the year and for August-September respectively. In August-September the pressure gradient between the high pressure over Greenland and the Greenland Sea low pressure is less strong than the annual average. Furthermore, comparison between the daily pressure in Figure 2 and the averages in Figure 3 reveals that for much of our study interval in 2010 the pressure does not follow the 'typical' pattern for the area, which is a high-pressure system over Greenland and an area of low pressure to the east of Svalbard (Tsukernik and others, 2009).

The beginning of the study interval (16 August 2010) was characterized by high pressure over the Greenland coast, with a ridge extending southwestward into the Fram Strait. Low-pressure zones located south of Iceland and east of Svalbard expanded and pushed the high-pressure zone northward on the 17th, but by the 18th it extended southward again.

In the first match (16-17 August 2010) the average flow direction is westward at an average speed of $0.17 \pm 0.12 \mathrm{~m} \mathrm{~s}^{-1}$. Clockwise flow around the core of the high-pressure zone in northeast Greenland created southerly winds, with a significant west-east shear, in the western Fram Strait that forced some of our westernmost floes northward (Fig. 2a), while those located more towards the centre of the strait were forced southward. Later on, under quiescent conditions, the ice was most likely advected by the EGC. Under such quiescent conditions it is also likely that local, sub-gridscale, katabatic winds off the northeast Greenland ice sheet, not resolved by the reanalysis, dominate, moving near-coastal ice floes offshore. We see this in several other image pairs, where, again, the prevailing winds weaken towards the Greenland coast.

Between 17 August (07:37) and 19 August 2010 (08:19) 22 objects were tracked. The vectors for this image pair (Fig. 2b) are the product of several episodes of movement related to changing wind direction. The average direction of movement is now $210 \pm 44^{\circ}$ (southwestward), while the average speed is $0.14 \pm 0.05 \mathrm{~m} \mathrm{~s}^{-1}$. This is likely to be a straightforward case of Ekman flow at $45^{\circ}$ to the right of the wind direction for the majority of the floes, with a few perhaps affected by small-scale ocean eddies.

On 18 August, southerly winds strengthen in the morning, fading again in the evening and then veering to northerlies on the morning of the 19th. From 19 to 21 August a high-pressure centre has moved south and over Greenland (Fig. 2c). Northerly winds persist until the 22nd, waning gradually in strength. On the 22 nd there are weak southerlies or westerlies which would cause floes to deviate from their flow towards the south (Fig. 2d).

In the image pair 19-20 August 2010 there were 15 objects tracked; the average direction of movement changed again, towards the south, with the exception of a couple of objects near the ice edge going in the opposite direction (Fig. 2c). Those offshore are more closely aligned with the wind vectors than those near the shore. As for the situation from 16 to 17 August 2010, it is possible that local katabatic winds may have been misaligned with the larger wind pattern on a spatial scale that cannot be resolved at the scale of the reanalysis dataset, causing these nearshore floe movements. Conditions were quiescent, so ocean currents may have been the dominant forcing at that time. Both the EGC and local ocean eddies may have affected floe movement, which seems relatively stagnant compared to that at the other time steps. Ekman flow may have been present in some vectors. Movement between 20 and 23 August 2010 was not dissimilar to the previous set of matches (Fig. 2d); winds were light and floes seemed relatively stationary.

Pressure was slightly lower on 23-24 August 2010, but there were no pressure centres in the region (Fig. 2e). Northerlies strengthened again on 24-25 August. Between 23 and 24 August, ice-floe motion turned towards the northeast, then returned southwest between 24 and 26 August (Fig. 2e and f). The movement northeast away from the fast-ice edge on 23 August went against the apparent direction and strength of the wind forcing, so we hypothesize this may have been due to local sub-gridscale katabatic winds off the Greenland ice sheet. It is worthy of note that several of the same objects have been tracked here as in the previous match. The ice-floe movement between 24 and 26 August 2010 was consistent with the wind direction.

Small lows and areas of medium to low pressure with lower pressure to the north and high pressure to the south persisted into 29 August 2010 (Fig. 2g). On 31 August a low formed in the eastern Fram Strait (Fig. 2h-i). Weak southerlies 

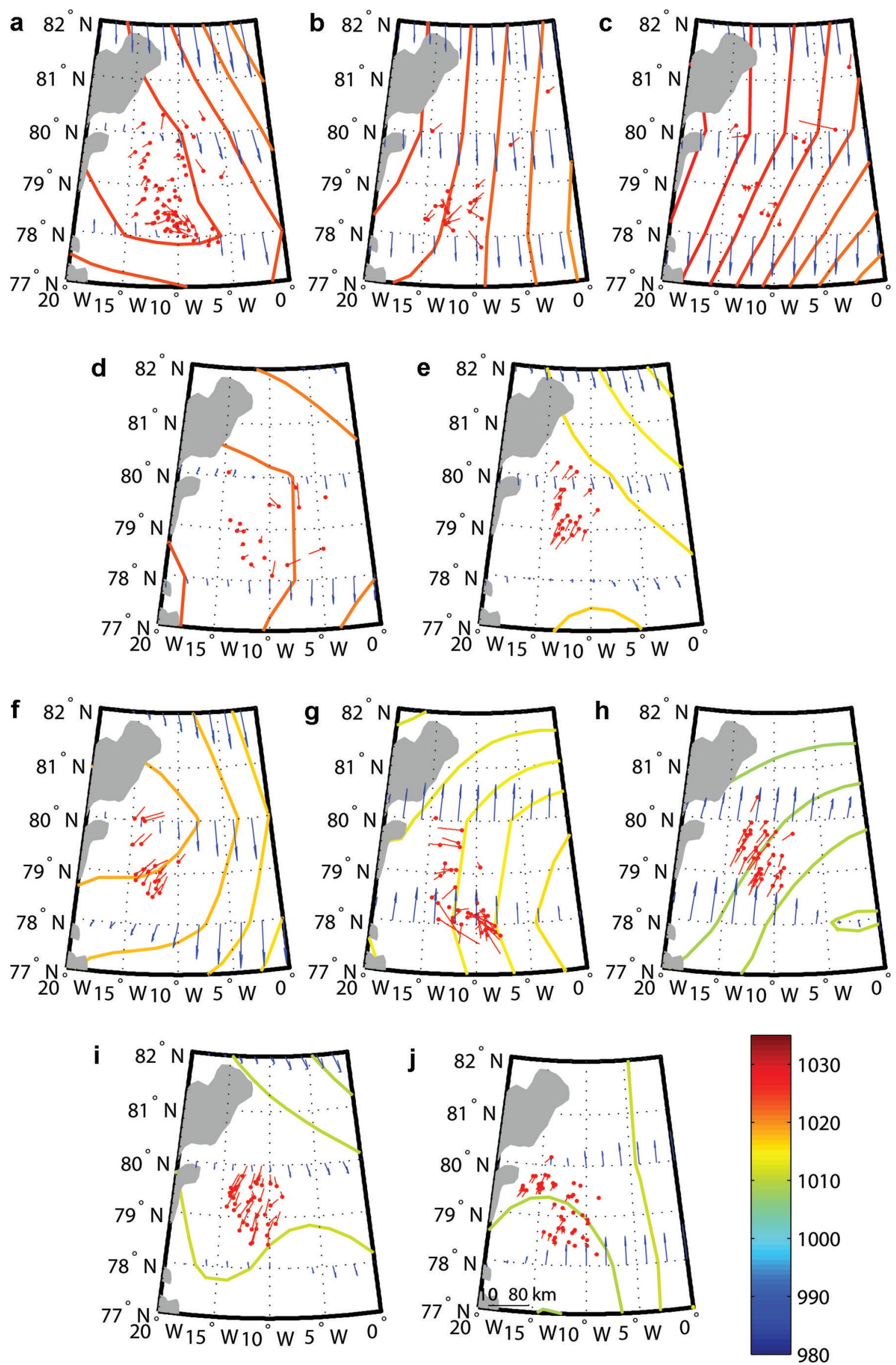

Fig. 2. A comparison of ice movement vectors produced by the ITSARI algorithm (in red, with a dot marking the end of the track) with winds representative of the period (in blue) and sea-level pressure (hPa; see scale bottom right) from the 20th-century reanalysis, all for 2010: (a) 16-17 August, reanalysis: 12:00 16 August; (b) 17-19 August, reanalysis: 06:00 19 August; (c) 19-20 August, reanalysis: 00:00 20 August; (d) 20-23 August, reanalysis: 12:00 22 August; (e) 23-24 August, reanalysis: 12:00 23 August; (f) 24-26 August, reanalysis: 00:00 26 August; (g) 26-30 August, reanalysis: 18:00 28 August; (h) 30-31 August, reanalysis: 18:00 30 August; (i) 31 August-2 September, reanalysis: 12:00 31 August; (j) 2-3 September, reanalysis: 12:00 2 September. 

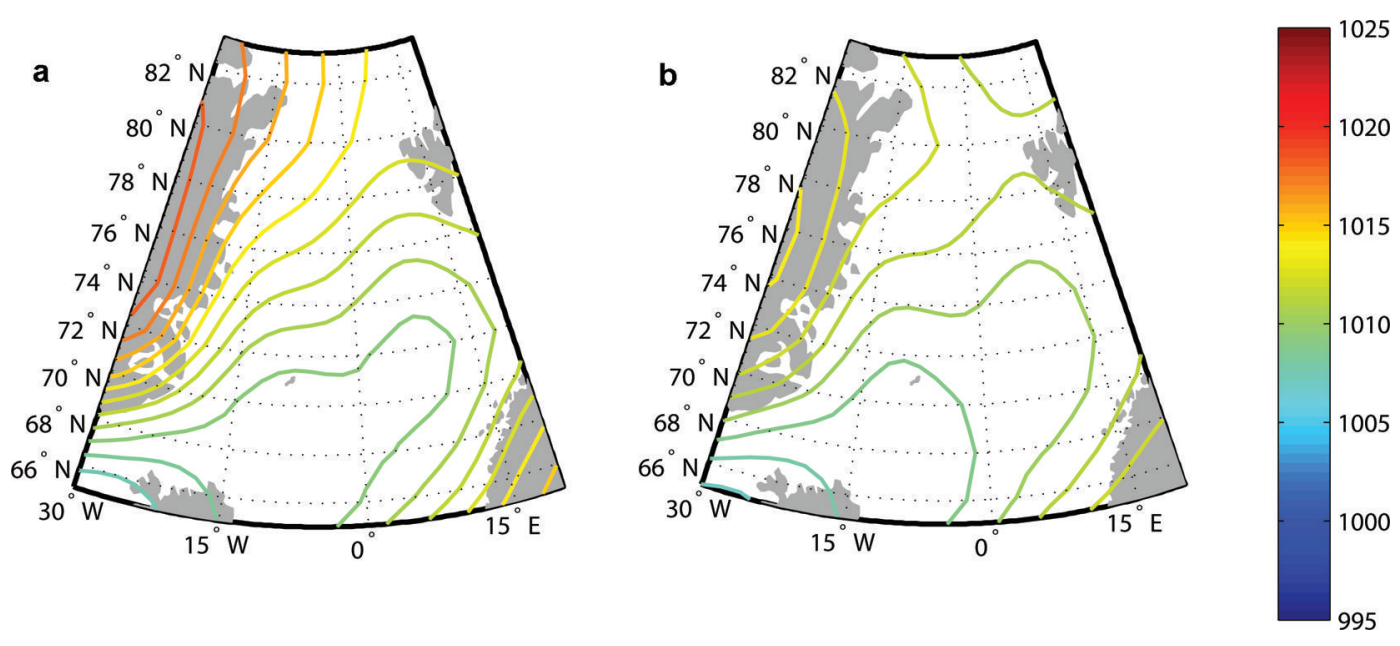

Fig. 3. Mean sea-level pressure (hPa) 1981-2010 for (a) all months and (b) August-September.

on 26 August strengthen on 27-28 August, weakening again on 29 August. There were two images from 30 August; each contained some of the objects from the image on 26 August. Vectors from both these matches are shown in Figure $3 \mathrm{~g}$. Between 26 August and the first image on 30 August 2010 (07:58) 21 objects were tracked. The average speed was $0.09 \pm 0.05 \mathrm{~m} \mathrm{~s}^{-1}$, towards the east and southeast, with vectors further north having a more easterly trajectory. Between 26 August and the second image on 30 August 2010 (07:59) 15 objects were tracked, some also having moved to the southeast but some others moving southwest.

Between 26 and 30 August 2010, movement is towards the east and southeast despite the wind having been predominantly from the south (Fig. $2 \mathrm{~g}$ ). It is important to be aware that this was over 4 days so the ice may have gone back and forth in that time, as the pressure systems changed rapidly from the passage of the lows mentioned above. Over this longer time period it is harder to relate ice movement to wind forcing because the wind is likely to have changed direction several times; we see instead the impact of the EGC becoming more obvious on a long temporal scale. Another factor is that these changes may be magnified by differences in movement of different floes becoming more pronounced over longer timescales; this could be contributing to why there appear to be floes moving in opposition to each other.

Thirty-seven objects were tracked between 30 and 31 August 2010 at an average speed of $0.38 \pm 0.07 \mathrm{~m} \mathrm{~s}^{-1}$, towards the northeast $\left(29^{\circ}\right)$ in perfect agreement with the apparent wind forcing (Fig. 2h). Between 31 August and 2 September 2010, 40 objects were tracked, moving southwest at an average speed of $0.15 \pm 0.05 \mathrm{~m} \mathrm{~s}^{-1}$ (Fig. 2i). In the final matching exercise in this set, between the images from 2 and 3 September 2010, 50 objects were tracked, again flow had reversed and the objects were heading back to the northeast (Fig. 2j). Between 31 August and 3 September a low forms in, and then moves away from, the Fram Strait, having led to strong changes in wind strength and direction over this time. It takes time for ice movement to respond to the wind forcing, so when the wind rapidly changed direction the ice motion appears erratic. From 31 August to 2 September the floes moved southwestward in response to weak winds on 31 August and early in the day on 1 September when the low was centred in the northeast of the strait, allowing the EGC to take over as the dominant forcing. Between 2 and 3 September 2010, floe movement was northward in response to strengthening southerlies.

\section{CONCLUSIONS}

Using the ITSARI algorithm we have tracked sea-ice motion at the individual floe scale in the western Fram Strait in late August-early September 2010. In contrast to other times of the year, when the Fram Strait wind field is characterized by strong and persistent northerlies, we show that the weaker, more variable winds typical of this period for the Fram Strait effectively slow the movement of sea-ice floes out of the area, thus slowing the export of ice from the Arctic Ocean at a crucial time for ice export, as the summer comes to an end. Under a regime of more persistent winds, especially for strong northerlies during late boreal summer, the Arctic Ocean could lose even more multi-year ice. This would leave the Arctic Ocean in an even more vulnerable position than at present with regard to the amount of multi-year ice present the following summer.

\section{ACKNOWLEDGEMENTS}

RADARSAT data courtesy of the Canadian Space Agency (RADARSAT-2 Data and Products copyright MacDONALD, DETTWILER AND ASSOCIATES LTD (2010) All Rights Reserved), by agreement with the Norwegian Meteorological Institute; 20th-century reanalysis V2 data provided by the US National Oceanic and Atmospheric Administration (NOAA) Office of Oceanic and Atmospheric Research (OAR)/Earth and Space Research Laboratory (ESRL) Physical Sciences Division (PSD), Boulder, CO, USA (http://www. esrl.noaa.gov/psd/). Support for the 20th-century reanalysis project dataset is provided by the US Department of Energy, Office of Science Innovative and Novel Computational Impact on Theory and Experiment (DOE INCITE) programme, and Office of Biological and Environmental Research (BER), and by the NOAA Climate Program Office. This work was part of Jennifer King's PhD project funded by Kongsberg Satellite Services.

\section{REFERENCES}

Brümmer B, Muller G, Affeld B, Gerdes R, Karcher M and F Kauker (2001) Cyclones over Fram Strait: impact on sea ice and 
variability. Polar Res., 20(2), 147-152 (doi: 10.3402/polar. v20i2.6511)

Brümmer B, Muller G and Hoeber H (2003) A Fram Strait cyclone: properties and impact on ice drift as measured by aircraft and buoys. J Geophys Res., 108, 4217-4230 (doi: 10.1029/ 2002JD002638)

Compo GP and 26 others (2011) The Twentieth Century Reanalysis Project. Q. J. R. Meteorol. Soc., 137(654), 1-28 (doi: 10.1002/ qj.776)

Hall JA, Bigg GR and Hall R (2012) Identification and tracking of individual sea ice floes from Envisat wide swath SAR images: a case study from the Fram Strait. Remote Sens. Lett., 3, 295-304 (doi: 10.1080/01431161.2011.583288)

Hansen E and 7 others (2013) Thinning of Arctic sea ice observed in Fram Strait: 1990-2011. J. Geophys. Res. - Oceans, 118, 5202-5221 (doi: 10.1002/jgrc.20393)

King JA (2012) Sea ice tracking from SAR in the Arctic. (PhD thesis, University of Sheffield)

Kwok R and Rothrock DA (1999) Variability of Fram Strait sea ice flux and North Atlantic Oscillation. J. Geophys. Res., 97, 2391-2402 (doi: 10.1029/1998JC900103)
Kwok R, Curlander JC and Pang SS (2004) Fram Strait sea ice outflow. J. Geophys. Res. - Oceans, 109(C1), C01009 (doi: 10.1029/2003JC001785)

Kwok R, Spreen G and Pang SS (2013) Arctic sea ice circulation and drift speed: decadal trends and ocean currents. J. Geophys. Res. - Oceans, 188(5), 2408-2425 (doi: 10.1002/ jgrc.20191)

Silva TAM and Bigg GR (2005) Computer based identification and tracking of Antarctic icebergs in SAR images. Remote Sens. Environ., 94, 287-297 (doi: 10.1016/j.rse.2004.10.002)

Smedsrud LH, Sirevaag A, Kloster K, Sorteberg A and Sandven S (2011) Recent wind driven high sea ice export in the Fram Strait contributes to Arctic sea ice decline. Cryosphere, 5, 821-829 (doi: 10.5194/tc-5-821-2011)

Tsukernik M, Deser C, Alexander M and Tomas R (2009) Atmospheric forcing of Fram Strait sea ice export: a closer look. Climate Dyn., 35, 1349-1360 (doi: 10.1007/s00382-0090647-z)

Vinje T (2001) Fram Strait ice fluxes and atmospheric circulation: 1950-2000, J. Climate, 14(16), 3508-3517 (doi: 10.1175/15200442(2001)014<3508:FSIFAA $>2.0 . C O ; 2)$ 